\title{
Isolasi dan Identifikasi Komponen Kimia Minyak Atsiri dari Daun, Batang dan Bunga Tumbuhan Salembangu (Melissa sp.)
}

\section{(Isolation and identification of chemical components of essential oils from leaves, stems, and flowers of Salembangu plants (Melissa sp.))}

\author{
Nurhaen $^{1 *}$ DessyWinarsii ${ }^{2)}$ Ahmad Ridhay ${ }^{1)}$ \\ 1) Lab. Kimia Organik Jurusan Kimia Fakultas MIPA, Universitas Tadulako \\ ${ }^{2)}$ Lab. Penelitian Jurusan Kimia Fakultas MIPA, Universitas Tadulako
}

\begin{abstract}
This study aims to determine the rendementand the chemical components of volatil oil from Salembangu plant (Melisa sp.) . variety of leaves, stems, and flowers were used as the sample. The volatil oil was isolated by doing stems-destilation. Process while the chemical component of volatile oil was analyzed with GC-MS. The result showed that the average volatil oil rendement of the leave, the steam and the flower were $0,51 \%, 0,29 \%$ and $0,90 \%$ respectively. The largest chemical component of volatil oil from the leave, the steam and the flower were curcumene,, 4-Terpineol and Syringol accondigly. The chemical component which characterized the Salembangu aroma was Zingeron.
\end{abstract}

Keywords: Salembangu Plant, Isolation, Rendement, Atsiri Oil.

\begin{abstract}
ABSTRAK
Penelitian ini bertujuan untuk mengetahui rendemen dan komponen kimia minyak atsiri tumbuhan Salembangu (Melissa sp.). Sampel yang digunakan adalah bagian daun, batang, dan bunga. Minyak atsiri tumbuhan Salembangu diperoleh dengan metode destilasi uap-air, kemudian destilatnya dipisahkan dengan corong pisah, sehingga diperoleh rata-rata rendemen minyak atsiri pada daun, batang, dan bunga berturut-turut sebesar 0,51\%, 0,29\%, 0,90\%. Analisis komponen kimia minyak atsiri tumbuhan Salembangu dilakukan dengan menggunakan Kromatografi Gas Spektrometri Massa (GC-MS). Komponen terbesar minyak atsiri tumbuhan Salembangu pada daun adalah kurkumin pada batang adalah 4-Terpineol dan pada bunga adalah Syringol. Senyawa yang mencirikan aroma khaspadatumbuhan Salembangu adalah Zingeron.
\end{abstract}

Kata Kunci: Tumbuhan Salembangu, Isolasi, Rendemen, Minyak Atsiri. 


\section{LATAR BELAKANG}

Minyak atsiri dikenal dengan minyak terbang, minyak eteris (essential oil atau volatil) atau minyak mudah menguap. Minyak atsiri dapat dihasilkan dari berbagai bagian tanaman, seperti akar, batang, ranting, daun, bunga, atau buah dan merupakan campuran dari senyawa-senyawa volatil yang dapat diperoleh dengan distilasi, pengepresan atau pun ekstraksi. Penghasil minyak atsiri berasal dari berbagai spesies tanaman yang sangat luas dan digunakan karena bernilai sebagai cita rasa dalam makanan dan minuman serta parfum dalam produk industri, obat-obatan dan kosmetik. Minyak atsiri tanaman diperoleh dari tanaman beraroma yang tersebar diseluruh dunia (Kardinan, 2005).

Minyak atsiri merupakan salah satu metabolit sekunder yang dihasilkan oleh tanaman tingkat tinggi dan mempunyai peranan penting bagi tanaman itu sendiri maupun bagi kehidupan manusia. Peranan minyak atsiri untuk kehidupan telah dikenal sejak lama. Seiring dengan kemajuan teknologi dalam bidang bahan alam maka usaha penggalian dan pemanfaatan minyak atsiri semakin meningkat (Guenther, 1947).

Minyak atsiri banyak diperlukan dalam kehidupan sehari-hari. Dengan kemajuan teknologi di bidang minyak atsiri, maka usaha penggalian sumber-sumber minyak atsiri dan kegunaannya dalam kehidupan manusia semakin meningkat. Minyak atsiri banyak digunakan sebagai obat-obatan. Untuk memenuhi kebutuhan itu, sebagian besar minyak atsiri diambil dari berbagai jenis tanaman penghasil minyak atsiri (Rumondang, 2004).

Wulan (2011), mengisolasi minyak atsiri dari tumbuhan Selasih pada batang, daun dan bunga dengan menggunakan metode destilasi uap. Prinsip kerja metode ini adalah air diisikan kedalam ketel uap dan bahan pada ketel suling. Rendemen minyak atsiri yang diperoleh pada batang sebesar $0,23 \%$, pada daun sebesar 0,48 \%, sedangkan pada bunga sebesar 0,94\%. Rendemen tertinggi terdapat pada bunga tumbuhan Selasih. Komponen terbanyak yang terkandung dalam minyak Selasih hutan pada daun adalah eugenol sedangkan pada batang dan bunga adalah caryophyllene.

Tumbuhan Salembangu (Melissa sp.) adalah tumbuhan liar yang tumbuh di perkebunan. Tumbuhaninimemilikibau yang wangi pada daun, batang dan bunga yang dapatdigunakansebagaibahanbakubarudalam produksi minyak atsiri ,namun ketidaktahuan masyarakat sehingga tumbuhan ini tidak termanfaatkan dengan baik.

\section{Isolasi dan Identifikasi Komponen Kimia Minyak Atsiri dari Daun, Batang dan Bunga Tumbuhan Salembangu (Melissa sp.)} (Nurhaen dkk) 


\section{BAHAN DAN METODE}

\section{Waktu dan Tempat}

Penelitian ini dilaksanakan di Laboratorium Penelitian Kimia Fakultas Matematika dan Ilmu Pengetahuan Alam Universitas Tadulako, Palu. Penelitian dimulai pada bulan Oktober sampai November 2013.

\section{Bahan dan Alat}

Bahan dasar yang digunakan dalam penelitian ini adalah daun, batang dan bunga tumbuhan Salembangu yang diperoleh dari Desa Lemusa Kecamatan Parigi Selatan Kabupaten Parigi Moutong. Bahan lain sebagai bahan pembantu mencakup air.

Peralatan yang digunakan terdiri atas : seperangkat alat destilasi uap - air, GC-MS, Pirolisis Shimadzu QP2010 dan alat-alat gelas yang umum digunakan dalam Laboratorium Kimia.

\section{Prosedur Kerja}

Penelitian ini dilaksanakan dalam tiga tahap, yaitu persiapan sampel, isolasi minyak atsiri dan penentuan komposisikimia minyak yang dihasilkan.

\section{Persiapan sampel}

Tumbuhan Salembangu (Melissa sp.) yang diambil daun, batang, dan bunga, diperoleh Masing-masing bagian dikemas dan disimpan untuk disuling atau diisolasi minyak atsirinya.

\section{Isolasi minyak atsiri}

Ketel penyulingan diisi dengan air sampai permukaan air berada tidak jauh di bawah saringan. Sampel daun, batang, dan bunga dimasukkan ke dalam ketel dengan berat tertentu. Ketel ditutup rapat dan dihubungkan dengan kondensor, adaptor dan penampungan. Ketel penyulingan dipanaskan hingga semua minyak atsiri telah terdestilasi. Minyak atsiri dalam destilat dipisahkan dari air dalam corong pemisah. Minyak atsiri yang dihasilkanditimbang kemudian diukur beratnya, ditentukan rendemen, dan dianalisis komposisi kimianya.

\section{Analisis Komponen Minyak Atsiri}

\section{Rendemen minyak atsiri}

Rendemen minyak atsiri yang dihasilkan dari daun, batang, dan bunga ditentukan menggunakan persamaan sebagai berikut :

Rendemen(\%)

$$
=\frac{\text { volume sampel minyak }(\mathrm{g})}{\text { berat sampel }(\mathrm{g})} \times 100 \%
$$

\section{Komposisi kimia minyak atsiri}

Komposisi kimia minyak atsiri ditentukan menggunakan metode GC-MS (Gas Chromatography - Mass Spectrometry). Cara pelaksanaannya sebagai berikut, peralatan GC-MS yang akan digunakan untuk GC dioperasikan pada suhu $60{ }^{\circ} \mathrm{C}$ 
selama 4 menit, kemudian dinaikkan suhunya menjadi $120{ }^{\circ} \mathrm{C}$ dengan kenaikan suhu $2{ }^{\circ} \mathrm{C}$ per menit. Pada suhu $120{ }^{\circ} \mathrm{C}$ dipertahankan selama 5 menit, kemudian dinaikkan lagi suhunya dengan kenaikan suhu $50{ }^{\circ} \mathrm{C}$ per menit sampai suhu akhir 290 ${ }^{\circ} \mathrm{C}$ dan dipertahankan selama 10 menit. Laju aliran gas total yang digunakan adalah $50 \mathrm{ml}$ per menit dengan slit ratio $1: 30$, suhu injektor $300{ }^{\circ} \mathrm{C}$ dan jumlah sampel disuntikkan ke injektor sebanyak $0,1 \mu 1$.

Untuk MS yang digunakan energi elektron sebesar $70 \mathrm{eV}$ dengan accelerating voltage sebesar 1,30 kV. Mass range yang dideteksi berkisar antara 40-400 $\mu \mathrm{g} / \mathrm{mol}$ dengan interval scanning 1 detik.

\section{HASIL DAN PEMBAHASAN}

Minyak atsiri pada daun, batang, dan bunga tumbuhan Salembangu diperoleh dengan metode destilasi uap-air karena metode ini paling sederhana yang hanya membutuhkan uap dengan jumlah tertentu untuk memisahkan minyak atsiri dari tanaman. Pada setiap bagian (daun, batang, dan bunga) perlakuan diulang sebanyak 2 kali sehingga diperoleh data sebagai berikut :

Tabe 1. Data hasil destilasi uap-air tumbuhan Salembangu pada daun, batang, dan bunga

\begin{tabular}{|c|c|c|c|c|c|}
\hline \multirow{2}{*}{ No } & \multirow{2}{*}{ Sampel } & \multicolumn{2}{|c|}{ (g) } & \multicolumn{2}{c|}{ Berat Minyak (g) } \\
\cline { 3 - 6 } & & I & II & I & II \\
\hline 1. & Daun & 600 & 600 & 2,986 & 3,251 \\
\hline
\end{tabular}

\begin{tabular}{|c|l|c|c|c|c|}
\hline 2. & Batang & 600 & 600 & 1,632 & 1,948 \\
\hline 3. & Bunga & 600 & 600 & 5,712 & 5,113 \\
\hline
\end{tabular}

Setiap perlakuan pada daun, batang, dan bunga disuling selama 8 jam karena diasumsikan bahwa dalam waktu tersebut minyak atsiri telah tersuling semuanya. Minyak atsiri yang diperoleh dari destilasi masih mengandung air sehingga harus dipisahkan. Menurut Guenther (1987), dalam setiap metode penyulingan bahan tumbuhan minyak atsiri hanya dapat diuapkan jika kontak langsung dengan panas. Minyak dalam jaringan mula-mula terekstraksi dari kelenjar tanaman dan selanjutnya terserap pada permukaan bahan melalui peristiwa osmosis.

Untuk memudahkan pemisahan antara minyak atsiri yang diperoleh dari air maka digunakan corong pisah. Dimana minyak akan berada di bagian atas sedangkan air berada di bagian bawah karena berat jenis air lebih besar dari pada berat jenis minyak. Setelah dilakukan pemisahan maka diperoleh rata-rata rendemen minyak atsiri sebagai berikut:

Tabel 2. Rendemen hasil proses destilasi uap-air pada daun, batang dan bunga tumbuhan Salembangu

\begin{tabular}{|c|l|c|c|c|}
\hline No & Sampel & $\begin{array}{c}\text { Rendemen } \\
\text { I } \\
(\%)\end{array}$ & $\begin{array}{c}\text { Rendemen } \\
\text { II } \\
(\%)\end{array}$ & $\begin{array}{c}\text { Rata-rata } \\
\text { Rendemen } \\
(\%)\end{array}$ \\
\hline 1. & Daun & $\mathbf{0 , 4 9}$ & $\mathbf{0 , 5 4}$ & $\mathbf{0 , 5 1}$ \\
\hline 2. & Batang & $\mathbf{0 , 2 7}$ & $\mathbf{0 , 3 2}$ & $\mathbf{0 , 2 9}$ \\
\hline 3. & Bunga & $\mathbf{0 , 9 5}$ & $\mathbf{0 , 8 5}$ & $\mathbf{0 , 9 0}$ \\
\hline
\end{tabular}


Hasil tersebut menunjukan bahwa minyak atsiri paling banyak terdapat pada bunga tumbuhan salembangu selanjutnya pada daun dan batang tumbuhan salembangu.

Komponen Kimia Minyak tumbuhan Salembangu

Untuk mengetahui komponen kimia minyak pada daun, batang, dan bunga tumbuhan salembangu dilakukan analisis menggunakan metode Gas ChromatographyMass Spectrometry (GC-MS). Prinsip dari GC-MS adalah pemisahan komponenkomponen dalam campuran dengan kromatografi gas dan tiap komponen dapat dibuat spektrum massa dengan ketelitian yang lebih tinggi. Hasil pemisahan dengan kromatografi gas dihasilkan kromatogram sedangkan hasil pemeriksaan spektrometri massa masing- masing senyawa disebut spektrum. Hasil yang diperoleh untuk daun salembangu ditunjukan pada gambar 1 .

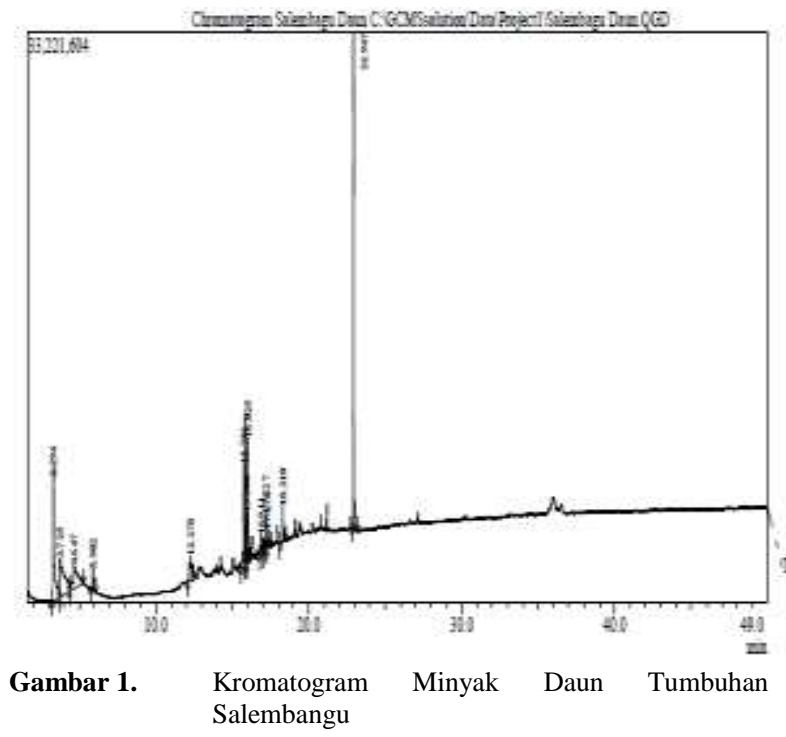

Gambar 1 Menunjukan bahwa hasil analisis GC-MS minyak daun tumbuhan salembangu yang diperoleh melalui penyulingan dengan cara uap-air terlihat 13 puncak yang menunjukkan bahwa terdapat 13 senyawa yang ada pada minyak daun tumbuhan Salembangu yang dihasilkan. Luas area puncak yang ada relative berbeda dengan demikian komponen kimia tersebut relative berbeda konsentrasinya. Dari ke 13 puncak yang terlihat hanya 6 puncak yang menunjukan senyawa minyak atsiri seperti yang ditunjukan pada tabel 3 .

Tabel 3. Hasil analisis GC-MS minyak daun tumbuhan Salembangu

\begin{tabular}{|c|c|c|c|}
\hline No & NamaSenyawa & $\begin{array}{c}\text { Waktu } \\
\text { Retensi }\end{array}$ & \% Area \\
\hline 1. & $1,8-C i n e o l$ & 12,278 & 5,44 \\
\hline 2. & Curcumene & 15,756 & 10,11 \\
\hline 3. & beta-Bisabolene & 15,908 & 1,52 \\
\hline 4. & $\begin{array}{c}\text { Sesquiphellandr } \\
\text { ene }\end{array}$ & 16,025 & 4,02 \\
\hline 5. & Zingerone & 16,911 & 2,32 \\
\hline 6. & Quinolin & 17,275 & 2,37 \\
\hline
\end{tabular}

Berdasarkan gambar 2, Hasil analisis kromatogram minyak atsiri pada daun tumbuhan Salembangu, menunjukan bahwa komponen kimia yang paling banyak terdapat pada minyak daun tumbuhan salembangu yaitu kurkumin (10,11\%), kemudian diikuti oleh 1,8-cineole $(5,44 \%)$, beta-sesquiphellandrene (4,02\%), Zingerone (2,32\%), quinolin (2,37\%), dan betaBisabolene (1,52\%). 


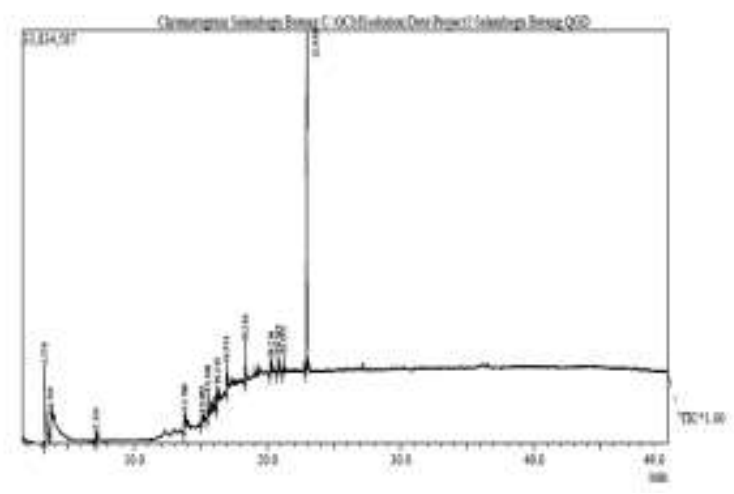

Gambar 2. Kromatogram minyak batang tumbuhan Salembangu

Pada gambar 2 Menunjukan bahwa hasil analisis GC-MS minyak batang tumbuhan salembangu yang diperoleh melalui penyulingan dengan cara uap-air terlihat 13 puncak yang menunjukkan bahwa terdapat 13 senyawa yang ada pada minyak batang tumbuhan Salembangu yang dihasilkan. Luas area puncak yang ada relatif berbeda dengan demikian komponen kimia tersebut relatif berbeda konsentrasinya. Dari 13 puncak yang terlihat hanya 6 puncak yang menunjukan senyawa minyak atsiri seperti yang ditunjukan pada tabel 4 .

Tabel 4. Hasil Analisis GC-MS minyak batang tumbuhan Salembangu

\begin{tabular}{|c|c|c|c|}
\hline No. & NamaSenyawa & $\begin{array}{c}\text { Waktu } \\
\text { Retensi }\end{array}$ & \% Area \\
\hline 1. & 4-Terpineol & 13,780 & 3,99 \\
\hline 2. & Eugenol & 15,092 & 1,52 \\
\hline 3. & Trans-Caryophyllene & 15,530 & 2,17 \\
\hline 4. & Zingerone & 16,911 & 2,92 \\
\hline 5. & Nortrachelogenin & 20,236 & 2,05 \\
\hline 6. & Trans-6-Shogaol & 20,769 & 2,48 \\
\hline
\end{tabular}

Kromatogram hasil analisis minyak atsiri pada batang tumbuhan salembangu yang terlihat pada tabel 4, menunjukan bahwa komponen kimia yang paling banyak terdapat pada minyak batang tumbuhan Salembangu yaitu 4-Terpineol (3,99\%), kemudian diikuti oleh Zingerone (2,92\%), trans-6-shogaol $(2,48 \%)$, trans-caryophyllene $(2,17 \%)$, nortrachelogenin $(2,05 \%)$, dan Eugenol (1,52 \%). (Handayani, 2011) menganalisis komponen terbesar minyak batang tumbuhan selasih hutan adalah senyawa caryophyllene. Senyawa caryophyllene juga merupakan salah satu senyawa yang terkandung pada minyak batang tumbuhan salembangu, dimana tumbuhan salembangu dan tumbuhan Selasih merupakan tumbuhan yang sejenis.

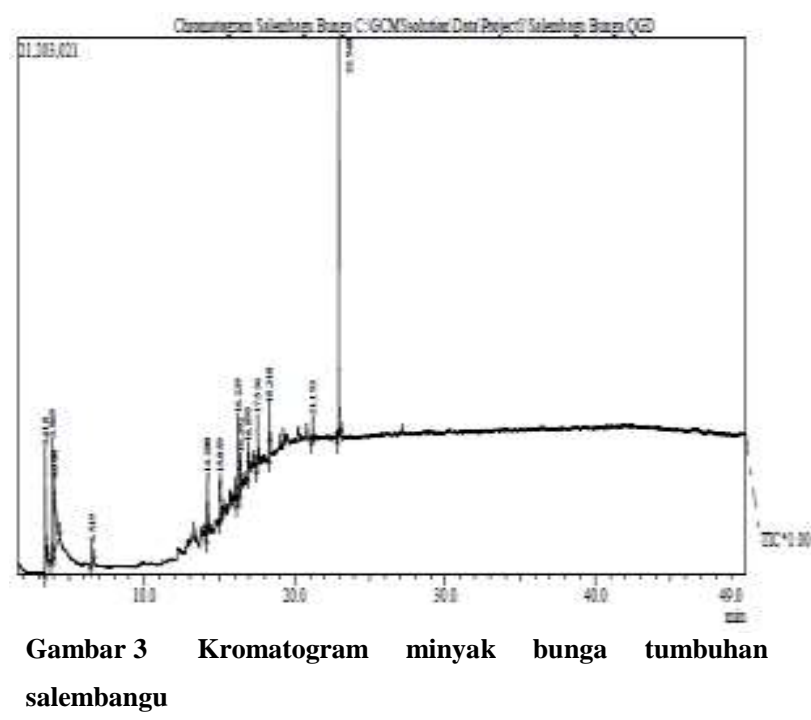

Gambar 3 Menunjukan bahwa hasil analisis GC-MS minyak batang tumbuhan salembangu yang diperoleh melalui penyulingan dengan cara uap-air terlihat 13 puncak yang menunjukkan bahwa terdapat 13 senyawa yang ada pada minyak batang tumbuhan Salembangu yang dihasilkan. Luas area puncak yang ada berbeda dengan 
demikian komponen kimia tersebut berbeda konsentrasinya. Dari 13 puncak yang terlihat hanya 4 puncak yang menunjukan senyawa minyak atsiri. Seperti yang ditunjukan pada tabel 6

Tabel 6 : Hasil Analisis GC-MS minyak bunga tumbuhan Salembangu

\begin{tabular}{|c|l|c|c|}
\hline No. & NamaSenyawa & WaktuRetensi & \% Area \\
\hline 1. & Syringol & $\mathbf{1 5 , 0 5 9}$ & $\mathbf{3 , 2 7}$ \\
\hline 2. & Zingerone & $\mathbf{1 6 , 8 9 9}$ & $\mathbf{1 , 4 4}$ \\
\hline \multicolumn{4}{c}{ Pada tabel 6 Hasil analisis }
\end{tabular}

kromatogram minyak atsiri pada batang tumbuhan salembangu, menunjukan bahwa komponen kimia yang paling banyak terdapat pada minyak batang tumbuhan salembangu yaitu syringol (3,27\%), kemudian diikuti oleh Zingeron (1,44\%).

Tabel 5. Persentase dan Komponen Kimia Minyak Daun, batang, dan bunga Tumbuhan Salembangu.

\begin{tabular}{|c|c|c|c|c|}
\hline \multirow[t]{2}{*}{ No } & \multirow[t]{2}{*}{ Jenis Senyawa } & \multicolumn{3}{|c|}{ Konsentrasi (\%) } \\
\hline & & Daun & Batang & Bunga \\
\hline 1. & 1,8-Cineol & 5,44 & - & - \\
\hline 2. & Curcumene & 10,11 & - & - \\
\hline 3. & beta-Bisabolene & 1,52 & - & - \\
\hline 4. & Sesquiphellandrene & 4,02 & - & - \\
\hline 5. & Zingerone & 2,32 & 2,92 & 1,44 \\
\hline 6. & Quinolin & 2,37 & - & - \\
\hline 7. & 4-Terpineol & - & 3,99 & - \\
\hline 8. & Eugenol & - & 1,52 & - \\
\hline 9. & $\begin{array}{c}\text { Trans- } \\
\text { Caryophyllene }\end{array}$ & - & 2,17 & - \\
\hline 10. & Nortrachelogenin & - & 2,05 & - \\
\hline 11. & Trans-6-Shogaol & - & 2,48 & - \\
\hline 12. & Syringol & - & - & 3,27 \\
\hline
\end{tabular}

Berdasarkan Hasil analisis komponen kimia minyak atsiri pada daun, batang, dan bunga tumbuhan salembangu tidak semua komponen utamanya sama hanya ada satu komponen yang sama terkandung pada daun, batang dan bunga yaitu zingerone dan senyawa ini dapat disimpulkan sebagai senyawa yang memberi aroma yang khas pada tumbuhan salembangu. Menurut Sthal dalam Kusumawati (2008), komposisi dari minyak atsiri sangat bervariasi tergantung dari tanaman penghasil, iklim, tanah tempat tumbuh, umur panen, metode ekstraksi, dan cara penyimpanan minyak.

Dari hasil analisis GC-MS diketahui bahwa komponen terbanyak yang terkandung dalam minyak tumbuhan salembangu pada bagian batang adalah 4Terpineol, pada daun adalah kurkumin dan pada bunga adalah syringol.

Berdasarkan hasil penelitian dan pembahasan, diperoleh kesimpulan sebagai berikut :

1. Rerata rendemen kandungan minyak atsiri pada daun sebesar $0,51 \%$, pada batang sebesar $0,29 \%$, dan pada bunga sebesar $0,90 \%$. Rerata rendemen terbesar terdapat pada bunga tumbuhan salembangu.

2. Berdasarkan hasil analisis GC-MS kandungan tertinggi minyak tumbuhan salembangu pada daun adalah curcumene, batang adalah 4-Terpineol, dan bunga adalah syringol.Senyawa yang mencirikan aroma pada tumbuhan 
salembangu adalah senyawa zingeron karena senyawa ini terdapat pada daun, batang, dan bunga.

\section{DAFTAR PUSTAKA}

Guenther, T. 1987. Minyak Atsiri. Terjemahan oleh Ketaren, S. 1990. Jakarta : UI.

Handayani, T.W., 2011. Isolasi dan Karakteristik Minyak Atsiri dari Tumbuhan Selasih Hutan. Skripsi Jurusan Kimia. FMIPA. Universitas Tadulako. Palu.

Kardinan, A., 2005. Budidaya dan Pasca Panen Tanaman penghasil minyak Atsiri. Agromedia Pustaka. Jakarta.

Kusumawati, F. A. 2008. Pencirian dan Aktifitas Penolak Serangga (insect repelent) Minyak atsiri Kulit Buah Jeruk Purut (Citrus hystrix) Kerin Terhadap Kutu Beras (Calandra oryzae L.). Skripsi Fakultas Farmasi. Universitas Surabaya. Surabaya.

Rumondang, B., 2004, Esterifikasi Patchouli Alkohol Hasil Isolasi Dari Minyak Daun Nilam (Patchouli Oil), Universitas Sumatera Utara. 


\section{Lampiran Contoh Perhitungan Rendemen Pada Bunga Tumbuhan Salembangu}

Diketahui : Berat Minyak 1 = 5,712 gr

$$
\text { Berat Bahan } 1=600 \text { gr }
$$

Ditanyakan : \% Rendemen ......?

Penyelesaian :

Rendemen $(\%)=\frac{\text { volume sampel minyak }(\mathrm{g})}{\text { berat } \operatorname{sampel}(\mathrm{g})} \times 100 \%$

$$
\begin{aligned}
& =\frac{5,712 \mathrm{gr}}{600 \mathrm{gr}} \times 100 \% \\
& =0,95 \%
\end{aligned}
$$

Diketahui : Berat Minyak 2 $=5,113 \mathrm{gr}$

$$
\text { Berat Bahan } 2=600 \text { gr }
$$

Ditanyakan : \% Rendemen ......?

Penyelesaian :

Rendemen $(\%)=\frac{\text { volume sampel minyak }(\mathrm{g})}{\text { berat } \operatorname{sampel}(\mathrm{g})} \times 100 \%$

$$
\begin{aligned}
& =\frac{5,113 \mathrm{gr}}{600 \mathrm{gr}} \times 100 \% \\
& =0,85 \%
\end{aligned}
$$

Rerata Rendemen $=\frac{\text { Rendemen } 1+\text { Rendemen } 2}{2}$

$$
\begin{aligned}
& =\frac{0,95 \%+0,85 \%}{2} \\
& =0,90 \%
\end{aligned}
$$

